\title{
Germline Mutations in Triple-Negative Breast Cancer
}

\author{
Eric Hahnen ${ }^{a}$ Jan Hauke ${ }^{a} \quad$ Christoph Engel $^{\mathrm{b}} \quad$ Guido Neidhardt $^{\mathrm{a}}$ Kerstin Rhiem $^{\mathrm{a}}$ \\ Rita K. Schmutzler ${ }^{\mathrm{a}}$ \\ ${ }^{a}$ Center for Hereditary Breast and Ovarian Cancer, Center for Integrated Oncology (ClO), Medical Faculty, University Hospital Cologne, \\ Cologne, Germany; \\ ${ }^{\mathrm{b}}$ Institute for Medical Informatics, Statistics and Epidemiology, University of Leipzig, Leipzig, Germany
}

\section{Keywords}

Triple-negative breast cancer - BRCA1 - BRCA2 - PALB2 . FANCM

\section{Summary}

Triple-negative breast cancer (TNBC) is associated with a poor prognosis and defines a subgroup of patients who do not benefit from endocrine or anti-HER2 therapy. Rather than being a biological entity, TNBC represents a heterogeneous disease, and further subtyping is necessary to establish targeted therapies. Germline mutational status may serve as a robust biomarker predicting therapy response, especially with respect to compounds challenging the DNA repair machinery. Patients with TNBC usually show an early onset of the disease, as well as a positive family history of breast and/or ovarian cancer in more than one third of all cases, which suggests that TNBC is closely associated with a hereditary disease cause. In unselected TNBC cases, the prevalence of pathogenic germline BRCA1/2 mutations is approximately twice as high as in breast cancer overall. Early age at diagnosis and positive family history are strong predictors for an increased $B R C A 1 / 2$ mutation probability, which is up to $40 \%$ when both risk factors are considered. Apart from $B R C A 1 / 2$, the rarely mutated breast cancer predisposition genes $P A L B 2$ and FANCM have been associated with TNBC. This review summarizes the role of germline mutational status in TNBC pathogenesis. Clinical trials addressing BRCA1/2 mutation carriers are discussed.

\section{Introduction}

The triple-negative breast cancer (TNBC) subtype is defined by a lack of estrogen receptor (ER), progesterone receptor (PR) and human epidermal growth factor receptor type 2 (HER2; ERBB2) amplification/overexpression, and is associated with a poor prognosis [1-3]. The triple-negative tumor phenotype is reported to account for $12-24 \%$ of all breast cancers [1, 4], with comparatively high prevalences observed in patients with African-American ethnicity [5]. TNBC defines a relevant subgroup of patients who require targeted therapeutic strategies as they do not benefit from endocrine or anti-HER2 therapy [6]. Rather than being a biological entity, TNBC is a heterogeneous disease, and subtyping is necessary to establish molecular-based therapies [7]. Different subgroups of TNBC have been identified on the basis of protein expression, mRNA signatures, and genomic alterations, either on the somatic and/or the germline level $[6,8,9]$. Clinical trials of targeted therapies (e.g., immune checkpoint inhibitors, androgen receptor inhibitors, poly(ADP-ribose)polymerase (PARP) inhibitors, vascular endothelial growth factor receptor inhibitors) and platinum-based therapies in TNBC are ongoing, which have recently been reviewed in detail $[6,10,11]$. Notably, the TNBC phenotype appears to be closely associated with a hereditary cause of the disease [4]. This notion is based on i) the generally early age of onset which is similar to that observed for patients carrying germline mutations in breast cancer predisposition genes, ii) the high rate of TNBC cases with a positive family history of cancer, iii) the high prevalence of germline mutations, and, vice versa, iv) the association of a small subset of breast cancer predisposition genes (e.g., BRCA1, BRCA2, PALB2, FANCM) with the TNBC phenotype [12-15]. Most breast cancer predisposition genes, including $B R C A 1 / 2$, are critical genes in the process of homologous recombination (HR) repair of double-strand DNA breaks [13, 16-19]. Heterozygous germline inactivation of HR genes may be accom-

\section{KARGER}

(c) 2017 S. Karger GmbH, Freiburg

Fax +497614520714 
panied by a somatic inactivation of the second allele, resulting in a HR deficiency and limited DNA repair capacities of the tumor cells [20]. There is increasing evidence that breast cancers arising in BRCA1/2 germline mutation carriers are associated with a better response to DNA-damaging treatment regimens [17, 21-25]. Thus, this short review aims to summarize the role of germline mutational status in TNBC pathogenesis, which may serve as a robust biomarker predicting therapy response, especially with respect to DNA-damaging compounds.

\section{TNBC Phenotype Associated with Early Disease Onset}

According to the National Cancer Institute (NIH) and the Robert Koch Institute (RKI), the overall mean age at first diagnosis for breast cancer is 62-64 years. In contrast, in unselected TNBC patients, the mean age at first diagnosis is considerably earlier, with reports ranging from 51 to 58 years [2, 26-31]. For Germany, the Munich Cancer Registry (www.tumorregister-muenchen.de/en/facts/ base/bC50f_E-ICD-10-C50-Breast-cancer-women-incidenceand-mortality.pdf) reported a TNBC phenotype in $8.6 \%$ of all breast cancers and in $19.8 \%$ of breast cancer cases with an age at onset before 40 years [32]. These data confirm a generally early disease onset for TNBC patients, an observation which is assumed to be driven by genetic predisposition. For example, breast cancer patients carrying pathogenic $B R C A 1$ or $B R C A 2$ germline mutations show a mean age of onset of 40 and 43 years [33], respectively, and patients carrying pathogenic PALB2 mutations have a mean age of onset of 53 years [14].

\section{TNBC and Family History}

In a large targeted sequencing study of mainly Caucasian TNBC patients, a positive family history was reported in 539 of 1,510 (35.7\%) unselected TNBC cases [26]. In this study, family history was defined as positive when at least 1 first- or second-degree relative was affected by breast cancer or ovarian cancer. In a cohort of unselected Hispanic women with TNBC, 56 of 146 (38.4\%) reported breast cancer in first- or second-degree relatives [34]. Concordant results were shown in an investigation of 207 unselected TNBC patients with different ethnicities [27]. In this study, a family history of breast or ovarian cancer was reported in 76 of 207 (36.7\%) cases, with a positive family history being defined as $\geq 1$ close blood relative (first-, second- or third-degree) with breast cancer at age $\leq 50$ years, or $\geq 1$ close blood relative with ovarian cancer [27]. Apart from the different ethnicities and the slightly different definitions of a positive family history applied in these studies, there is compelling evidence that more than one-third of all TNBC patients have a familial background of breast and/or ovarian cancer when first- and second-degree relatives are taken into account.

\section{Elevated Prevalence of BRCA1/2 Mutations in TNBC}

While germline BRCA1/2 mutations are found in $5.3 \%$ of unselected breast cancers according to The Cancer Genome Atlas [28], a study by Couch et al. [26] showed that $11.2 \%$ of unselected TNBC cases had deleterious mutations in the BRCA1 (8.5\%) and BRCA2 (2.7\%) gene, respectively. Of note, TNBC patients with mutations showed a younger age at first diagnosis and had higher-grade tumors than those without mutations [26]. A mean age at first diagnosis of 44 and 47 years was reported for TNBC patients with BRCA1 and BRCA2 mutations, respectively, while TNBC patients without pathogenic germline mutations show a mean age at first diagnosis of 51 years. In summary, even TNBC cases unselected for a positive family history of cancer and/or early disease onset appear to be enriched for deleterious germline mutations in $B R C A 1 / 2$. In other studies, the BRCA1/2 mutation frequencies of unselected TNBC patients vary between 9.4 and 18.2\% (table 1) [26, 27, 29-31, 35-37].

\section{High Prevalence of BRCA 1/2 Mutations in Early-On- set and/or Familial TNBC}

When stratified by family history, the study by Couch et al. [26] revealed that 66 of 539 (12.2\%) TNBC patients with a family history of cancer carry pathogenic BRCA1/2 mutations, compared to 83 of $969(8.6 \%)$ patients without a family history of cancer. More pronounced differences were observed when stratified by disease onset. A total of 78 of 386 (20.2\%) BRCA1/2 mutation carriers were observed in the subgroup of TNBC patients with a disease onset before age 40 compared to 94 of $1,122(8.4 \%)$ patients with a disease onset $\geq$ age 40. Similar differences were observed in the GeparSixto trial (NCT01426880) [38]. In this study, 31 BRCA1/2 mutation carriers were observed among $110(28.2 \%)$ TNBC patients with a positive family history of cancer compared to only 19 of 181 (10.5\%) patients without a positive family history of cancer. In the subgroup of patients with a disease onset before age 40, 23 of 65 (35.4\%) were shown to carry a pathogenic BRCA1/2 gene mutation compared to 27 of 226 (11.9\%) patients with a disease onset $\geq$ age 40 . Similarly, an investigation of a genetic counseling cohort revealed a $43.8 \%$ (64/146) prevalence of $B R C A 1 / 2$ mutation carriers among TNBC patients with an age at first diagnosis of $<40$ years [39]. Thus, $B R C A 1 / 2$ mutation frequencies appear to be generally high in early-onset and/or familial TNBC cases. The inclusion criteria of the German Consortium for Hereditary Breast and Ovarian Cancer (GC-HBOC) for genetic $B R C A 1 / 2$ testing consider both, family history and disease onset (table 2). According to the data generated by the GC-HBOC as of November 2016, a total of 16,979 breast cancer index patients with known receptor status fulfill these criteria, of which 3,234 (19\%) carry pathogenic BRCA1/2 mutations. Among these 16,979 familial index cases, 3,662 (21.6\%) patients with a TNBC tumor phenotype were observed (mean age at onset: 42.7 years), of which 1,254 (34.2\%) carried pathogenic BRCA1 and 174 (4.8\%) pathogenic BRCA2 alterations, clearly demonstrating that the cohort of early-onset/familial TNBC is enriched for BRCA1/2 mutation carriers. 
Table 1. $B R C A 1 / 2$ mutation prevalences in triple-negative breast cancer (TNBC) patients not selected for age at first diagnosis or family history of breast and/or ovarian cancer

\begin{tabular}{lcccc}
\hline $\begin{array}{l}\text { TNBC cases } \\
\text { (unselected), } \mathrm{n}\end{array}$ & $\begin{array}{l}\text { Proportion BRCA1 } \\
\text { positive, } \mathrm{n}(\%)\end{array}$ & $\begin{array}{l}\text { Proportion } B R C A 2 \\
\text { positive, } \mathrm{n}(\%)\end{array}$ & $\begin{array}{l}\text { Proportion BRCA1/2 } \\
\text { positive, } \mathrm{n}(\%)\end{array}$ & Reference \\
\hline 77 & $11(14.3)$ & $3(3.9)$ & $14(18.2)$ & {$[29]$} \\
199 & $13(6.5)$ & $8(4.0)$ & $21(10.6)$ & {$[30]$} \\
990 & $71(7.2)^{\mathrm{a}}$ & $22(2.2)^{\mathrm{a}}$ & $93(9.4)^{\mathrm{a}}$ & {$[35]$} \\
1,824 & $155(8.5)^{\mathrm{a}}$ & $49(2.7)^{\mathrm{a}}$ & $204(11.2)^{\mathrm{a}}$ & {$[26]$} \\
291 & $43(14.7)$ & $7(2.4)$ & $50(17.1)$ & {$[36]$} \\
105 & $13(12.4)$ & $2(1.9)$ & $15(14.3)$ & {$[37]$} \\
774 & $44(5.7)^{\mathrm{a}}$ & $30(3.9)^{\mathrm{a}}$ & $74(9.9)^{\mathrm{a}}$ & {$[31]$} \\
207 & $23(11.1)^{\mathrm{b}}$ & $9(4.3)^{\mathrm{b}}$ & $32(15.5)^{\mathrm{b}}$ & {$[27]$} \\
\hline
\end{tabular}

a Study does not cover larger deletions/duplications (copy number variations, CNVs) within the BRCA1/2 genes.

${ }^{\mathrm{b}}$ Only a subset of patients was screened for CNVs. According to a GeparSixto investigation, pathogenic CNVs in the BRCA1/2 genes were found in approximately $1.7 \%$ of unselected TNBC patients [36].

\section{Still a Matter of Debate: Germline BRCA1/2 Testing in Sporadic TNBC Patients}

According to the National Institute for Health and Care Excellence (NICE), genetic $B R C A 1 / 2$ testing is recommended when the combined $B R C A 1$ and $B R C A 2$ mutation carrier probability is $\geq 10 \%$ [27]. Given the comparatively high $B R C A 1 / 2$ mutation frequency even in unselected TNBC cases, an incorporation of the TNBC subtype in guidelines for genetic testing is discussed. According to the National Comprehensive Cancer Network and the American Society of Breast Surgeons, BRCA1/2 testing is generally recommended for women with TNBC diagnosed at age $\leq 60$ years, irrespective of a positive cancer family history [27]. However, the age-dependent $B R C A 1 / 2$ mutation carrier probability was largely unknown for TNBC patients without family history, and the data presented by Couch et al. [26] suggests a BRCA1/2 mutation carrier probability below the recommended $10 \%$ threshold in sporadic TNBC cases with an age at first diagnosis of $<60$ years. Our recent $B R C A 1 / 2$ germline analysis of 802 TNBC patients without a family history of breast and/or ovarian cancer suggests that the BRCA1/2 mutation prevalence exceeds the threshold of $10 \%$ in sporadic TNBC patients with an age at diagnosis of $<50$ years (manuscript in preparation) [32]. However, the confidence interval in the group with an age at first diagnosis of 40-49 years requires confirmation. The finding that a subgroup of BRCA1/2-positive patients with TNBC do not show a positive family history may be explained by disease modifiers that are independent from BRCA1/2 [4], de novo mutations, or limited family structures.

\section{Other Predisposition Genes Associated with TNBC Phenotype}

Many of the other genes involved in HR repair are now recognized to also contribute to hereditary breast and/or ovarian cancer risk, including ATM, BRIP1, CHEK2, NBN, PALB2, RAD51C, and $R A D 51 D$, while only limited evidence is available for BARD1, FANCM, MRE11A, and RAD50 [13, 15, 17-19, 40]. Notably, only
Table 2. 'Positive family history' as defined by the inclusion criteria of the German Consortium for Hereditary Breast and Ovarian Cancer (GC-HBOC) for BRCA1 and BRCA2 germline testing

$\geq 3$ women with breast cancer

$\geq 2$ women with breast cancer, 1 with onset below 51 years of age

$\geq 1$ woman with breast cancer and 1 woman with ovarian cancer

$\geq 2$ women with ovarian cancer

$\geq 1$ woman with breast- and ovarian cancer

$\geq 1$ woman with breast cancer below 36 years of age

$\geq 1$ woman with bilateral breast cancer with onset below 51 years

$\geq 1$ male with breast cancer and 1 woman with breast or ovarian cancer

BRCA1, BRCA2, PALB2, and FANCM have so far been associated with the TNBC phenotype [12-15]: Approximately 66-70\% of breast cancers arising in BRCA1 mutation carriers and up to 16$23 \%$ of breast cancers in BRCA2 carriers are triple-negative [35, 41]. A recent analysis of patients positive for PALB2 germline mutations revealed $34 \%$ being triple-negative. For FANCM, higher mutation frequencies were observed in TNBC cases versus breast cancer cases not selected for tumor phenotype [13, 15]. Other breast cancer risk genes such as CHEK2 and probably ATM are unlikely to predispose for TNBC [42]. With the rise of next generation sequencing, germline testing is nowadays not restricted to $B R C A 1 / 2$ and covers the above-named and further genes that predispose for rare cancer predisposition syndromes [40]. Besides $B R C A 1 / 2$, the study by Couch et al. [26] analyzed 15 'non$B R C A 1 / 2$ ' cancer predisposition genes (i.e., ATM, BARD1, BRIP1, CDH1, CHEK2, MRE11A, NBN, PALB2, PTEN, RAD50, RAD51C, $R A D 51 D, S T K 11, T P 53, X R C C 2)$. Deleterious mutations in non$B R C A 1 / 2$ genes were detected in only $3.7 \%$ of unselected TNBC patients, while PALB2 mutations prevailed (21/1,828; $1.1 \%)$.

\section{Germline Mutation Status as Biomarker for Therapy Response}

Approximately $9-18 \%$ of unselected TNBCs and up to $40 \%$ of the early-onset and/or familial TNBC cases may be explained by 
germline mutations in BRCA1, BRCA2 and, to a much smaller extent, $P A L B 2$ and possibly other risk genes. There is increasing evidence that breast and also ovarian cancers arising in BRCA1 and $B R C A 2$ germline mutation carriers are attributed to a better response to DNA-damaging treatment regimens [17, 21-24], including PARP inhibitors [23]. The PARP inhibitor olaparib is currently under investigation in $B R C A 1 / 2$ germline mutation carriers with HER2-negative primary breast cancer (OlympiA study, NCT02032823). Favorable response rates to DNA-damaging compounds are also likely for patients carrying germline mutations in other predisposition genes intimately involved in HR repair, as recently shown for ovarian carcinomas [25]. Thus, mutational status might be considered as a valuable biomarker to predict therapy response also in TNBC. In a neoadjuvant trial, it was shown that platinum-based chemotherapy is highly effective in BRCA1 germline mutation carriers, i.e., $61 \%$ of 82 TNBC patients experienced a pathologic complete response (pCR) following cisplatin singleagent therapy [21]. The high sensitivity of BRCA1/2 mutation carriers to platinum-based chemotherapy [21] is in line with data in the metastatic or recurrent locally advanced setting where carbopl- atin monotherapy revealed significantly higher response rates in $B R C A 1 / 2$ mutation carriers compared with patients without $B R C A 1 / 2$ mutations [43]. The GeparSixto trial revealed that germline BRCA1/2 mutation status predicts higher pCR rates after neoadjuvant anthracycline/taxane-based chemotherapy in TNBC. Given the fact that germline testing in TNBC patients is widely recommended even in the absence of a positive family history, the germline mutation status might be easily available and should implicitly be considered for clinical management.

\section{Acknowledgement}

This work was supported by German Cancer Aid (No. 110837).

\section{Disclosure Statement}

$\mathrm{EH}, \mathrm{KR}$, and RKS received honoraria for scientific advisory board meetings from Astra Zeneca. The other authors declared no conflicts of interest.

\section{References}

1 Metcalfe K, Lubinski J, Lynch HT, et al.: Family history of cancer and cancer risks in women with BRCA1 or BRCA2 mutations. J Natl Cancer Inst 2010;102:18741878.

2 Dent R, Trudeau M, Pritchard KI, Hanna WM, Kahn HK, Sawka CA, Lickley LA, Rawlinson E, Sun P, Narod SA: Triple-negative breast cancer: clinical features and patterns of recurrence. Clin Cancer Res 2007;13:44294434

3 Liedtke C, Mazouni C, Hess KR, Andre F, Tordai A, Mejia JA, Symmans WF, Gonzalez-Angulo AM, Hennessy B, Green M, Cristofanilli M, Hortobagyi GN Pusztai L: Response to neoadjuvant therapy and longterm survival in patients with triple-negative breast cancer. J Clin Oncol 2008;26:1275-1281.

4 Stevens KN, Vachon CM, Couch FJ: Genetic susceptibility to triple-negative breast cancer. Cancer Res 2013; 73:2025-2030.

5 Kwan ML, Kushi LH, Weltzien E, Maring B, Kutner SE, Fulton RS, Lee MM, Ambrosone CB, Caan BJ: Epidemiology of breast cancer subtypes in two prospective cohort studies of breast cancer survivors. Breast Cancer Res 2009;11:R31.

6 Denkert C, Liedtke C, Tutt A, von Minckwitz G: Molecular alterations in triple-negative breast cancer - the road to new treatment strategies. Lancet 2016; Epub ahead of print.

7 Lehmann BD, Bauer JA, Chen X, Sanders ME, Chakravarthy AB, Shyr Y, Pietenpol JA: Identification of human triple-negative breast cancer subtypes and preclinical models for selection of targeted therapies. J Clin Invest 2011;121:2750-2767.

8 Shah SP, Roth A, Goya R, et al.: The clonal and mutational evolution spectrum of primary triple-negative breast cancers. Nature 2012;486:395-399.

$\checkmark$ Ademuyiwa FO, Tao Y, Luo J, Weilbaecher K, Ma CX: Differences in the mutational landscape of triple-negative breast cancer in African Americans and Caucasians. Breast Cancer Res Treat 2017;161:491-499.
10 Harbeck N, Gnant M: Breast cancer. Lancet 2016;Epub ahead of print.

11 Bianchini G, Balko JM, Mayer IA, Sanders ME, Gianni L: Triple-negative breast cancer: challenges and opportunities of a heterogeneous disease. Nat Rev Clin Oncol 2016;13:674-690.

12 Easton DF, Pharoah PD, Antoniou AC, Tischkowitz M, Tavtigian SV, Nathanson KL, Devilee P, Meindl A, Couch FJ, Southey M, Goldgar DE, Evans DG, Chenevix-Trench G, Rahman N, Robson M, Domchek SM, Foulkes WD: Gene-panel sequencing and the prediction of breast-cancer risk. N Engl J Med 2015;372: 2243-2257.

13 Kiiski JI, Pelttari LM, Khan S, Freysteinsdottir ES, Reynisdottir I, Hart SN, Shimelis H, Vilske S, Kallioniemi A, Schleutker J, Leminen A, Butzow R, Blomqvist C, Barkardottir RB, Couch FJ, Aittomaki K, Nevanlinna $\mathrm{H}$ : Exome sequencing identifies FANCM as a susceptibility gene for triple-negative breast cancer. Proc Natl Acad Sci U S A 2014;111:15172-15177.

14 Cybulski C, Kluzniak W, Huzarski T, Wokolorczyk D, Kashyap A, Jakubowska A, Szwiec M, Byrski T, Debniak T, Gorski B, Sopik V, Akbari MR, Sun P, Gronwald J, Narod SA, Lubinski J; Polish Hereditary Breast Cancer Consortium: Clinical outcomes in women with breast cancer and a PALB2 mutation: a prospective cohort analysis. Lancet Oncol 2015;16:638-644.

15 Neidhardt G, Hauke J, Ramser J, et al.: Association between loss-of-function mutations within the FANCM gene and early-onset familial breast cancer. JAMA Oncol 2016;Epub ahead of print.

16 Chornokur G, Lin HY, Tyrer JP, et al.: Common genetic variation in cellular transport genes and epithelial ovarian cancer (EOC) risk. PloS One 2015;10:e0128106.

17 Walsh CS: Two decades beyond BRCA1/2: homologous recombination, hereditary cancer risk and a target for ovarian cancer therapy. Gynecol Oncol 2015; 137:343-350.
18 Meindl A, Hellebrand H, Wiek C, Erven V, Wappenschmidt B, Niederacher D, Freund M, Lichtner P, Hartmann L, Schaal H, Ramser J, Honisch E, Kubisch C, Wichmann HE, Kast K, Deissler H, Engel C, Muller-Myhsok B, Neveling K, Kiechle M, Mathew CG, Schindler D, Schmutzler RK, Hanenberg H: Germline mutations in breast and ovarian cancer pedigrees establish RAD51C as a human cancer susceptibility gene. Nat Genet 2010;42:410-414

19 Ramus SJ, Song H, Dicks E, et al.; AOCS Study Group; Cicek MS, Cunningham JM, Fridley BL, et al.; Ovarian Cancer Association Consortium; Odunsi K, Whittemore AS, Karlan BY, Dork T, Goode EL, Menon U, Jacobs IJ, Antoniou AC, Pharoah PD, Gayther SA: Germline mutations in the BRIP1, BARD1, PALB2, and NBN genes in women with ovarian cancer. J Natl Cancer Inst 2015;107(11).

20 Severson TM, Peeters J, Majewski I, Michaut M, Bosma A, Schouten PC, Chin SF, Pereira B, Goldgraben MA, Bismeijer T, Kluin RJ, Muris JJ, Jirstrom K, Kerkhoven RM, Wessels L, Caldas C, Bernards R, Simon IM, Linn S: BRCA1-like signature in triple negative breast cancer: molecular and clinical characterization reveals subgroups with therapeutic potential. Mol Oncol 2015;9:1528-1538.

21 Byrski T, Huzarski T, Dent R, Marczyk E, Jasiowka M, Gronwald J, Jakubowicz J, Cybulski C, Wisniowski R, Godlewski D, Lubinski J, Narod SA: Pathologic complete response to neoadjuvant cisplatin in BRCA1positive breast cancer patients. Breast Cancer Res Treat 2014;147:401-405.

22 Audeh MW, Carmichael J, Penson RT, Friedlander M, Powell B, Bell-McGuinn KM, Scott C, Weitzel JN, Oaknin A, Loman N, Lu K, Schmutzler RK, Matulonis U, Wickens M, Tutt A: Oral poly(ADP-ribose) polymerase inhibitor olaparib in patients with BRCA1 or BRCA2 mutations and recurrent ovarian cancer: a proof-of-concept trial. Lancet 2010;376:245-251. 
23 Ledermann J, Harter P, Gourley C, Friedlander M, Vergote I, Rustin G, Scott CL, Meier W, ShapiraFrommer R, Safra T, Matei D, Fielding A, Spencer S, Dougherty B, Orr M, Hodgson D, Barrett JC, Matulonis U: Olaparib maintenance therapy in patients with platinum-sensitive relapsed serous ovarian cancer: a preplanned retrospective analysis of outcomes by BRCA status in a randomised phase 2 trial. Lancet Oncol 2014;15:852-861.

24 Tutt A, Robson M, Garber JE, Domchek SM, Audeh MW, Weitzel JN, Friedlander M, Arun B, Loman N, Schmutzler RK, Wardley A, Mitchell G, Earl H, Wickens M, Carmichael J: Oral poly(ADP-ribose) polymerase inhibitor olaparib in patients with BRCAl or BRCA2 mutations and advanced breast cancer: a proof-of-concept trial. Lancet 2010;376:235-244.

25 Pennington KP, Walsh T, Harrell MI, Lee MK, Pennil CC, Rendi MH, Thornton A, Norquist BM, Casadei S, Nord AS, Agnew KJ, Pritchard CC, Scroggins S, Garcia RL, King MC, Swisher EM: Germline and somatic mutations in homologous recombination genes predict platinum response and survival in ovarian, fallopian tube, and peritoneal carcinomas. Clin Cancer Res 2014; 20:764-775.

26 Couch FJ, Hart SN, Sharma P, et al.: Inherited mutations in 17 breast cancer susceptibility genes among a large triple-negative breast cancer cohort unselected for family history of breast cancer. J Clin Oncol 2015; 33:304-311.

27 Sharma P, Klemp JR, Kimler BF, Mahnken JD, Geier LJ, Khan QJ, Elia M, Connor CS, McGinness MK, Mammen JM, Wagner JL, Ward C, Ranallo L, Knight CJ, Stecklein SR, Jensen RA, Fabian CJ, Godwin AK: Germline BRCA mutation evaluation in a prospective triple-negative breast cancer registry: implications for hereditary breast and/or ovarian cancer syndrome testing. Breast Cancer Res Treat 2014;145:707-714.

28 Cancer Genome Atlas Network: Comprehensive molecular portraits of human breast tumours. Nature 2012;490:61-70.

29 Gonzalez-Angulo AM, Timms KM, Liu S, Chen H, Litton JK, Potter J, Lanchbury JS, Stemke-Hale K, Hennessy BT, Arun BK, Hortobagyi GN, Do KA, Mills GB, MericBernstam F: Incidence and outcome of BRCA mutations in unselected patients with triple receptor-negative breast cancer. Clin Cancer Res 2011;17:1082-1089.

30 Hartman AR, Kaldate RR, Sailer LM, Painter L, Grier CE, Endsley RR, Griffin M, Hamilton SA, Frye CA, Silberman MA, Wenstrup RJ, Sandbach JF: Prevalence of BRCA mutations in an unselected population of triplenegative breast cancer. Cancer 2012;118:2787-2795.
31 Wong-Brown MW, Meldrum CJ, Carpenter JE, Clarke CL, Narod SA, Jakubowska A, Rudnicka H, Lubinski J, Scott RJ: Prevalence of BRCA1 and BRCA2 germline mutations in patients with triple-negative breast cancer. Breast Cancer Res Treat 2015;150:71-80.

32 Rhiem K, Engel C, Engel J, Niederacher D, Sutter C, Varon-Mateeva R, Steinemann D, Arnold N, Dworniczak B, Wang-Gohrke S, Gehrig A, Wappenschmidt B, Meindl A, Schmutzler RK: BRCA1/2 mutation prevalence in triple-negative breast cancer patients without family history of breast and ovarian cancer. J Clin Oncol 2016;34(suppl):abstr 1090.

33 Kotsopoulos J, Lubinski J, Gronwald J, Cybulski C, Demsky R, Neuhausen SL, Kim-Sing C, Tung N, Friedman S, Senter L, Weitzel J, Karlan B, Moller P, Sun P, Narod SA; Hereditary Breast Cancer Clinical Study Group: Factors influencing ovulation and the risk of ovarian cancer in BRCA1 and BRCA2 mutation carriers. Int J Cancer 2015;137:1136-1146.

34 Anderson K, Thompson PA, Wertheim BC, Martin L, Komenaka IK, Bondy M, Daneri-Navarro A, MezaMontenegro MM, Gutierrez-Millan LE, Brewster A, Madlensky L, Tobias M, Natarajan L, Martinez ME: Family history of breast and ovarian cancer and triple negative subtype in Hispanic/Latina women. Springerplus 2014;3:727.

35 Zhang J, Sun J, Chen J, Yao L, Ouyang T, Li J, Wang T, Fan Z, Fan T, Lin B, Xie Y: Comprehensive analysis of BRCA1 and BRCA2 germline mutations in a large cohort of 5,931 Chinese women with breast cancer. Breast Cancer Res Treat 2016;158:455-462.

36 Von Minckwitz G, Hahnen E, Fasching PA, Hauke J, Schneeweiss A, Salat C, Rezai M, Blohmer JU, Zahm DM, Jackisch C, Gerber B, Klare P, Kummel S, Eidtmann H, Paepke S, Nekljudova V, Loibl S, Untch M, Schmutzler RK: Pathological complete response (pCR) rates after carboplatin-containing neoadjuvant chemotherapy in patients with germline BRCA (gBRCA) mutation and triple-negative breast cancer (TNBC): results from GeparSixto. J Clin Oncol 2014;32:(suppl): abstr 1005.

37 Gonzalez-Rivera M, Lobo M, Lopez-Tarruella S, Jerez Y, del Monte-Millan M, Massarrah T, Ramos-Medina R, Ocana I, Picornell A, Garzon SS, Perez-Carbornero L, Garcia-Saenz JA, Gomez H, Moreno F, MarquezRodas I, Fuentes H, Martin M: Frequency of germline DNA genetic findings in an unselected prospective cohort of triple-negative breast cancer patients participating in a platinum-based neoadjuvant chemotherapy trial. Breast Cancer Res Treat 2016;156:507-515.
38 Von Minckwitz G, Schneeweiss A, Loibl S, Salat C, Denkert C, Rezai M, Blohmer JU, Jackisch C, Paepke S, Gerber B, Zahm DM, Kummel S, Eidtmann H, Klare P, Huober J, Costa S, Tesch H, Hanusch C, Hilfrich J, Khandan F, Fasching PA, Sinn BV, Engels K, Mehta K, Nekljudova V, Untch M: Neoadjuvant carboplatin in patients with triple-negative and HER2-positive early breast cancer (GeparSixto; GBG 66): a randomised phase 2 trial. Lancet Oncol 2014;15:747-756.

39 Greenup R, Buchanan A, Lorizio W, Rhoads K, Chan S, Leedom T, King R, McLennan J, Crawford B, Kelly Marcom P, Shelley Hwang E: Prevalence of BRCA mutations among women with triple-negative breast cancer (TNBC) in a genetic counseling cohort. Ann Surg Oncol 2013;20:3254-3258.

40 Easton DF, Pharoah PD, Antoniou AC, Tischkowitz M, Tavtigian SV, Nathanson KL, Devilee P, Meindl A, Couch FJ, Southey M, Goldgar DE, Evans DG, Chenevix-Trench G, Rahman N, Robson M, Domchek SM, Foulkes WD: Gene-panel sequencing and the prediction of breast-cancer risk. N Engl J Med 2015;372: 2243-2257.

41 Couch FJ, Wang X, McGuffog L, et al.; kConFab Investigators, Radice P, Schmutzler RK; SWE BRCA, Domchek SM, Piedmonte M, Singer CF, et al.; Ontario Cancer Genetics Network, Hansen TV, Neuhausen SL, Szabo CI, et al.; HEBON, EMBRACE, Frost D, Ellis S, Fineberg E, et al.; GEMO Study Collaborators, Zlowocka-Perlowska E, Gronwald J, Lubinski J, et al. BCFR, Benitez J, Senter L, Huo D, et al.; CIMBA: Genome-wide association study in BRCA1 mutation carriers identifies novel loci associated with breast and ovarian cancer risk. PLoS Genet 2013;9:e1003212.

42 Schmidt MK, Hogervorst F, van Hien R, et al.: Ageand tumor subtype-specific breast cancer risk estimates for chek2*1100delc carriers. J Clin Oncol 2016; 34:2750-2760.

43 Tutt A EP, Kilburn L, Gillett C, Pinder S, Abraham J, Barrett S, Barrett-Lee P, Chan S, Cheang M, Dowsett M, Fox L, Gazinska P, Grigoriadis A, Gutin A, Harper-Wynne C, Hatton M, Kernaghan S, Lanchbury J, Morden J, Owen J, Parikh J, Parker P, Rahman N, Roylance R, Shaw A, Smith I, Thompson R, Timms K, Tovey H, Wardley A, Wilson G, Harries M, Bliss J: TNT: a randomized phase III trial of carboplatin compared with docetaxel for patients with metastatic or recurrent locally advanced triple negative or BRCA1/2 breast cancer. SABCS Dec 9-13, 2014, S3-01, San Antonio, TX. 